\title{
Endüstriyel Sistemlerde Arkaplan Çıkarımı Tabanlı Hareketli Nesne Tespiti ve Sayılması için Yeni Bir Yaklaşım
}

\author{
Mehmet KARAKÖSE ${ }^{1} \mathscr{\&}$, Mehmet BAYGIN $^{1}$, İlhan AYDIN ${ }^{1}$, Alişan SARIMADEN ${ }^{1}$, Erhan AKIN \\ ${ }^{1}$ Bilgisayar Mühendisliği, Fırat Üniversitesi, Elazı̆̆, Türkiye \\ $\varangle$ : mkarakose@ firat.edu.tr
}

Geliş (Received): 10.09.2016

Kabul (Accepted): 29.12.2016

\begin{abstract}
ÖZET: Bilgisayarlı görme ve görüntü işleme yaklaşımları günümüzde endüstriyel kontrol sistemlerinde oldukça önemli bir yer tutmaktadır. Özellikle kalite kontrol sistemlerinde kullanılan bilgisayarlı görme teknolojisi bir üretim hattında üretilen ürünlerin hızlı, sorunsuz ve doğru bir şekilde kontrol edilmesi açısından oldukça büyük öneme sahiptir. Klasik metotlarla yapılan kontrollerin getireceği problemler göz önüne alındığında bilgisayarlı görme kavramının ehemmiyeti daha net bir şekilde anlaşılacaktır. Bu çalışmada bilgisayarlı görme tabanlı kalite kontrolü için yeni bir metot önerilmiştir. Önerilen metot bir üretim hattından geçen ürünlerin görüntülerini kaydeder. Üretim bandından geçen bu ürünler saniyede 60 görüntü karesi (fps) hızına sahip bir kamera aracıllğıyla kaydedilmiştir. Önerilen yaklaşımda alınan görüntüler öncelikle bazı morfolojik işlemlerden geçirilerek ürünlerin detaylarının net bir şekilde ortaya çıkarılması sağlanmıştır. Daha sonra Gaussian karışım modeli ile arkaplanı çıkarılarak hareket eden nesneler tespit edilmiştir. Daha sonra belirlenen bölgeden nesnelerin geçip geçmediği kontrol edilerek saydırma işlemi yapılmışır. Birbirine yakın veya üst üste binmiş olan nesnelerin doğru şekilde saydırılması için Convex hull yöntemi ile nesnelerin kontur'ü çizdirilmiş ve nesnelerin alanına göre alandan çoklu nesne geçip geçmediği tespit edilmiştir. Önerilen bu yaklaşım ile yüksek hıza sahip üretim bantlarında geçen ürünlerin eksiksiz ve sorunsuz bir şekilde sayımı gerçekleştirilmiş olup, elde edilen deneysel sonuçlar ile algoritmanın etkili ve doğru sonuçlar verdiği gözlemlenmiştir.
\end{abstract}

Anahtar Kelimeler: Bilgisayarlı Görme, Nesne Sayma, Yüksek Hızlı Görüntü İşleme, Endüstriyel Uygulamalar.

\section{A New Approach for Background Subraction Based Moving Object Detection and Counting in Industrial Systems}

\begin{abstract}
In recent years, computer vision and image processing approaches hold a very important place in industrial control systems. Especially, the computer vision technique used in the quality control of products in a production line has a great importance in terms of controlling of products fast, smoothly and correctly. When it is considered problems brought up by the inspections carried out by conventional methods, the importance of computer vision concept will be understood more clearly. In this study, a new method was proposed for computer vision based quality control. The proposed method records images of products passed on a production line as a video. These products were counted by using high speed image processing techniques. Products passed on a production line were recorded by using a camera with 60 frame per second (fps). In the proposed method, the images taken in the proposed approach are firstly subjected to some morphological operations to reveal the details of the products clearly. Then, moving objects were detected by removing the background with Gaussian mixture model. Then, it is checked whether or not the objects in the determined area have passed, and the process of counting is performed. The contours of the objects are drawn with Convex hull method and it is determined whether multiple objects pass over the area according to the area of the objects. The counting of the products in high speed production line was performed successfully and completely and the experimental results show that the algorithm is effective and accurate results.
\end{abstract}

Keywords: Computer Vision, Object Counting, High Speed Image Processing, Industrial Applications.

\section{GíRiş}

Bilgisayar görmesi, seri üretim hatlarında ürün sayma, hatalı ürün kontrolü gibi çeşitli temel işlemlerde sıklıkla kullanılan bir yapıdır [1]. Genellikle bant üzerinde geçen ürünlerde herhangi bir eksiklik olup olmadığını tespit etmek amaciyla kullanılan bu sistemler, yüksek performansta çalı̧̧makta ve bir uzman tarafindan yapılan kontrole göre oldukça önemli avantajlar sunmaktadır. Bir uzman tarafindan sağlanan bu kontroller genellikle hatalara sebebiyet verdiğinden günümüzdeki endüstriyel sistemlerde bilgisayar görmesi tabanlı kalite kontrol sistemleri daha çok tercih edilmektedir [2-3]. 
Bilgisayar görmesi tabanlı kalite kontrol sistemleri otomobil, ambalaj, montaj hattı, tekstil gibi birçok farklı endüstriyel alanda en temel donanım olarak görev yapmaktadır [1-3, 7-16]. Her bir alanda farklı farklı işlevlere sahip olan kalite kontrol sistemleri en temel görevleri açısından ürünlerdeki eksiklikleri tespit etme, ürünleri sayma, ürünlerin boyutlarını belirleme olarak sınıflandırılabilmektedir. Bu konu üzerine literatürde yapılan çalışmalar incelendiğinde sistemlerin genel olarak üretim bandından bir ürün geçtiğinde görüntü aldığı ve bu görüntü üzerinde çeşitli algoritmaları yürüttüğü görülmektedir. Ayrıca gerçekleştirilen bu işlemler yüksek performanslı kameralar kullanılarak yapılmakta ve genellikle endüstriyel tabanlı bir bilgisayar üzerinden yürütülmektedir [4]. Bu sistem çerçevesinde yürütülen algoritmalar ise genellikle örüntü tanıma ve sinıflandırma tabanlıdır [5-6]. Bu sayede aynı özelliklere sahip ürünler hatalı olanlardan ayrıştırılabilmekte, ürünler saydırılabilmekte ve özelliklerine göre sınıflandırılabilmektedir.

Bilgisayar görmesi tabanlı kalite kontrol sistemleri alanında yapılan birçok çalışma mevcuttur. $\mathrm{Bu}$ çalışmaların birinde, kâğıt paraların kontrolüne yönelik bir uygulama geliştirilmiştir. Kâğıt paralar üzerindeki eksikliklerin tespitine yönelik yapılan bu çalışma ile yeni bir görüntü bölütleme algoritması önerilmiştir. Çalışmada kâğıt paraya gömülü olarak bulunan örüntüler ultraviyole 1 şık altında incelenmekte ve herhangi bir sıkıntı olup olmadığı tespit edilmektedir [1]. Bu alanda gerçekleştirilen bir başka çalışmada ise şişe kapaklarının yüzeylerindeki eksiklikleri tespit edebilmek amacıyla hılı bir tespit algoritması geliştirilmiştir. Çalışmada öncelikli olarak bir kamera aracılığıyla alınan görüntülerden kapağı içeren belirli bir bölge alınmaktadır. Daha sonra alınan bu görüntüde özellik eşleştirmesi yapabilmek amacıyla histogram çıkarımı yapılmaktadır. Son olarak önerilen yaklaşım ile eksikliklerin boyutu ve pozisyonu tespit edilmektedir. Endüstriyel ortamda yapılan deneysel çalışmalar ile önerilen yaklaşımın çıktıları ve doğruluğu kanıtlanmıştır [7]. Konu üzerine gerçekleştirilen bir diğer çalışmada ise resimli çiniler üzerinde meydana gelen kusurların tespit edilmesi amaçlanmıştır. Çalışmada sekiz farklı kusur çeşidinin belirlenmesi hedeflenmiştir. Yine bu amacı gerçekleştirebilmek için yapay sinir ağı yapısı kurulmuş ve eksikliklerin sınıflandırılmasında bu metot kullanılmıştır. Çalışmada \%90 oranında başarı sağlanarak eksikliklerin tespit edilmesi sağlanmıştır [8].Makine görmesi tabanlı gerçekleştirilen uygulamada bir üretim bandından geçen şişelerin kapakları ve bu şişelerdeki sıvıların seviyeleri birlikte kontrol edilmiştir [9]. Önerilen bu yaklaşım şişe kapakları için üç farklı durum, sıvı seviye kontrolü için de üç farklı durum kontrolü yapmaktadır. Sistem temel olarak sıvı seviyesi ve kapak durumunun doğru olduğu durumlarda kabul değeri üretirken, aksi durumlarda bant üzerinden geçen ürün için ret değeri vermektedir.

Literatürde yapılan çalışmalar farklı alanlarda uygulama alanı bulmuştur. Yapılan çalışmalardaki temel problem hız, doğruluk ve farklı sistemlere kolayca uyarlamadır.
Arka plan çıkarımı tabanlı yöntemler nesne saymak için genellikle her çerçevede belirlenen bir çizgiden nesnenin geçip geçmediğini kontrol etmektedir. Bu yöntem hızlı ve birbirine yakın geçen nesnelerin sayılmasında yanlış çalışmaktadır.

$\mathrm{Bu}$ çalışmada nesne tespiti, sayma ve boyut tespitini birlikte yapmak için Gaussian karışım tabanlı yeni bir yöntem önerilmiştir. Gaussian karışım modeli ile nesne arka planı çıkarıldıktan sonra genişleme, açma ve kapama gibi morfolojik özellikler ile gürültüler giderilerek nesnelerdeki delikler kapatılmaktadır. Nesne sayma işlemi için ise çizgi kullanmak yerine yeni bir yöntem olarak bir bölgeden nesnenin geçip geçmediği kontrol edilmektedir. Eğer belirlenen bölgede önceki çerçevede nesne var ve mevcut çerçevede yok ise sayma işlemi yapılmaktadır. Bu özellik daha doğru sayma işlemi yapılmasını sağlamaktadır. Ayrıca nesnelerin görüntü momentleri hesaplanarak convex hull yöntemi ile boyutları da belirlenmektedir. Böylece birbirine yakın nesnelerin sayılması esansında oluşabilecek hatalar da azaltılmıştır. Çalışmada kullanılan video görüntüsü yaklaşık 60 fps hıza sahip olup, önerilen yaklaşım $\mathrm{C}++$ programlama dili ve Open CV kütüphanesi kullanılarak ortaya konmuştur. Yapılan testlerde önerilen yaklaşımın doğruluğu sağlanmış ve ürünlerin doğru bir şekilde tespit edildiği görülmüştür.

$\mathrm{Bu}$ kapsamda makalenin ikinci bölümünde kalite kontrol sistemlerin temel yapısı incelenmiş olup, üçüncü bölümde önerilen yaklaşımın detayları sunulmuştur. Dördüncü bölümde deneysel sonuçlara yer verilmiş ve son bölümde sonuçlar ile gelecek çalışmalara ilişkin bilgiler sunulmuştur.

\section{Kalite Kontrol Sistemleri}

Makine görmesi tabanlı kalite kontrol sistemleri uzun yıllardan beri kullanılan ve sürekli gelişme eğiliminde olan yapılardır. Özellikle hassas kontrol ve tespit gerektiren alanlarda kullanilan bu sistemler kullanıcılarına önemli derecede avantaj ve hız sağlamaktadır. Teknolojinin gelişmesiyle de beraber yüksek hızlı çözümler sağlayan kalite kontrol sistemleri ile birçok endüstriyel alanda otomatikleştirilmiş denetleme sistemleri oluşturulabilmektedir. Tablo 1'de kalite kontrol sistemleriyle ilgili yapılmış çalışmalar ve bu çalışmaların ilgili olduğu endüstriyel alanlar detaylı bir şekilde sunulmuştur.

Tablo 1'den de görülebileceği üzere kalite kontrol sistemleri günlük yaşantıda sıklıkla kullanılan birçok endüstriyel ürünü kontrol etmek amaciyla kullanılabilmektedir. $\mathrm{Bu}$ durumun en önemli sebebi, kalite kontrol sistemlerinin bir uzman tarafindan yapılan kontrollere göre çok daha hızlı, daha az maliyetli ve daha hassas ölçüm yapabilmesidir. Gelişen teknolojiye paralel olarak kullanımı artan bu sistemler kullanıcılarına her geçen gün daha çok özelliğe sahip çözümler sunmaktadır. Ayrıca kullanıcıların kendi ihtiyaçlarına göre bu sistemleri değiştirebilmesi yine kalite kontrol sistemlerinin bir diğer avantajıdır. 
Tablo 1. Kalite kontrol sistemleri üzerine çeşitli endüstriyel gerçekleştirilen çalışmalar

\begin{tabular}{lllll} 
No & Çalışma alanı & Çalışmanın Kapsamı & Referans \\
\hline 1 & Baskı endüstrisi & Kâğıt paralar üzerindeki eksikliklerin kontrolü & {$[1]$} \\
2 & İnşaat endüstrisi & Köprüler üzerindeki eksikliklerin otomatik teftişi & {$[2]$} \\
3 & Gıda endüstrisi & Et, peynir gibi gıdaların sınıflandırılması & {$[3,10,11]$} \\
4 & Paketleme endüstrisi & Şişe kapaklarının yüzeylerindeki eksikliklerin ve sıvı seviyelerinin tespit edilmesi & {$[7,9]$} \\
5 & Televizyon Endüstrisi & Kamera hareket parametrelerinin tahmin edilmesi & {$[12]$} \\
6 & Tekstil endüstrisi & Fabrikalarda üretilen kumaşlardaki eksikliklerin tespit edilmesi & {$[13,14,15]$} \\
7 & Çelik endüstrisi & Üretilen çeliklerin yüzeylerinde meydana gelen aşınmaların tespit edilmesi & {$[16]$} \\
8 & Sanat & Doku özelliği analizine dayalı basılı çinilerin eksiklerinin tespit edilmesi & {$[8]$}
\end{tabular}

Kalite kontrol sistemlerinin bu kadar gelişimine katk1 sağlayan en temel eleman yüksek performanslı kameraların üretimidir [17].

Günümüzde kameralar şahıs kullanımının yanı sıra endüstriyel alanlarda da kullanılmaktadır. Özellikle yüksek çözünürlüklü ve yüksek hızlı görüntü duyargaların gelişmesi bu durumun en önemli sebeplerindendir [18-23].

Ayrıca görüntü duyargalarının üretim maliyetlerinin düşmesi ve kullanıcılar tarafından kolay erişilebilir bir hale gelmesi bu durumu tetikleyen bir diğer faktördür. Şekil 1'de kalite kontrol sistemleri için kullanılan bir kameranın temel arabirimleri sunulmuştur [17-19].

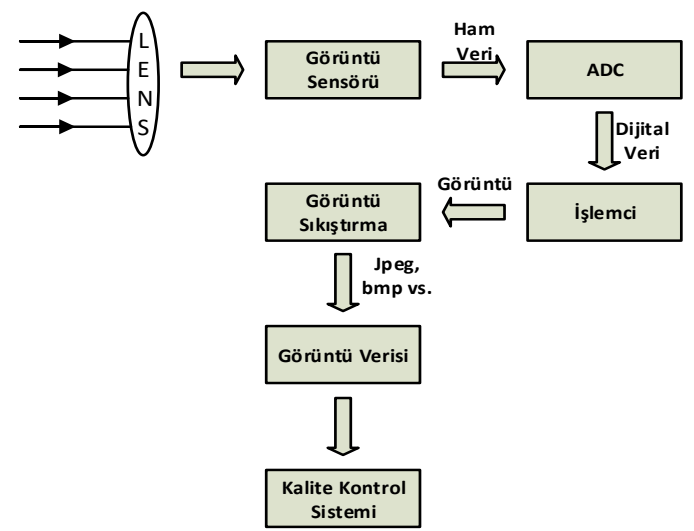

Şekil 1. Kamera sisteminin temel içyapısı

Şekil 1'den de görülebileceği üzere temel bir kamera sistemi 3 ana bölümden oluşmaktadır. Bu bölümlerden ilki olan lens, bir objeden yansıyan 1şı̆̆ görüntü sensoru üzerine düşüren ve o nesnenin görüntüsünün oluşmasına yardımcı olan bir elemandır. İkinci bölümde ise görüntü sensörleri bulunmaktadır. Genel olarak görüntü sensörleri CMOS ve CCD olmak üzere iki tiptedir. CCD temel olarak kaliteli görüntüler sunarken, CMOS sensörler kaliteli görüntüler sunmalarının yanında ucuz maliyetli çözümler açısından tercih sebebi olabilmektedir. Bir kamera sisteminin üçüncü bölümü ise işlemci kısmıdır.
Endüstriyel kamera sistemlerinde genellikle FPGA kullanılmasına rağmen gelişen teknolojiyle beraber daha farklı yapıda ve hızda işlemciler de kullanılabilmektedir.

\section{Arka Plan Çıkarımı Tabanlı Nesne Tespiti}

Bir görüntüdeki hareket eden nesnelerin sayılması ve tespiti için üç yöntemden faydalanılmaktadır. Bunlar optik akış, ardışık çerçevelerin farkı ve arka plan çıkarımıdır. Optik akış piksel seviye yoğunluğunu tahmin ederek hareketli nesneleri tespit eder. Nesne tespiti için herhangi bir ön bilgiye ihtiyaç duymaz. Bu yöntem kamera hareket halindeyken iyi sonuçlar vermesine rağmen, çok fazla hesaplama gerektirdiğinden gerçek zamanlı sistemler için uygun değildir. Çerçeve farkı ise ardışık iki çerçeve arasındaki piksellerin yoğunluk değişimine göre hareket tahmini yapmaktadır. $\mathrm{Bu}$ yöntem dinamik ortamlarda iyi sonuç vermesine rağmen, arka plan ve ön alan rengi birbirine yakın olduğunda bu yöntem yanlış sonuçlar vermekte ve tespit edilen nesnede oluşan boşluklar kapanmamaktadır.

Arka plan çıkarımı hareket eden veya durağan bir nesnenin tespiti için etkin bir yöntemdir. Nesne tespiti arka plan ile ön alan farkı değerlendirilerek yapılır. Arka plan çıkarımının başarımı arka plan modelleme ve güncelleme yöntemine bağlıdır. .

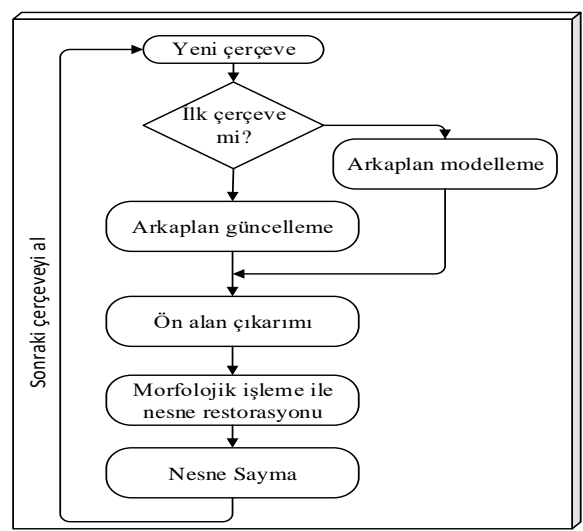

Şekil 2. Önerilen yöntemin sistem diyagramı 
$\mathrm{Bu}$ çalışmada endüstride hareket eden ürünlerin sayılması ve nesne tespiti için gaussian karışım modeli tabanlı bir yöntem önerilmiştir. Önerilen yöntem ile ilk olarak arkaplan modeli oluşturulmakta ve Gaussian karışım modeli ile güncellenmektedir. Daha sonra arkaplan çıkarımı yapılarak aktif nesneler tespit edilmektedir. Önerilen yöntemin blok şeması Şekil 2'de verilmiştir

Önerilen yöntemde, arka plan çıkarımı metodu ile hareket eden nesnelerin tespiti yapılmaktadır. Arka plan çıkarımında ön alan ve arka plan görüntüsü arasındaki fark ile elde edilmektedir.

Kameradan alınan görüntüler renkli görüntüler olup çok boyutlu bir uzaya gerek vardır. Alınan her bir çerçeve RGB formatında olup çok değişkenli Gauss dağılımı ile ifade edilmelidir. Bu dağılım denklem (1) ile verilmiştir.

$$
\begin{aligned}
& G\left(x \mid \mu_{k}, \sigma^{2}\right)=\frac{1}{(2 \pi)^{d / 2}|\Sigma|^{1 / 2}} x \\
& e^{-\frac{1}{2}(x-\mu)^{T} \Sigma^{-1}(x-\mu)}
\end{aligned}
$$

Denklem (1)'de d parametresi boyutu, $\mu$ ortalamayı ve $\Sigma$ ise dxd boyutlu kovaryans matrisini göstermektedir. Renkli görüntüler ile çalışıldığından d parametresi 3 alınmıştır. Gaussian karışım modeli çok modlu bir dağılım için tanımlayıcı olarak kullanılabilir. Gaussian karışım modeli $\mathrm{K}$ bileşenden oluşmakta olup modelin olasılık yoğunluk fonksiyonu aşağıdaki gibi tanımlanabilir.

$$
P(x)=\sum_{j=1}^{K} w_{j} G\left(x \mid \mu_{j}, \sigma^{2}\right)
$$

Denklemde $w_{j}$ tek bir Gaussian dağılımın ağırlığını göstermektedir. Her aşamada model güncellenerek yoğunluk tekrar hesaplanmaktadır. Denklemde $\mu_{k}$ ve $\sigma^{2}$ sirasıyla tahmin edilen ortalama değer ve varyansı göstermektedir. Gaussian dağılım kümeleri eğitilerek $w_{j}$ için fark değerleri arka plan görüntüsündeki her bir piksel için uygulanır. Bir piksel var olan $\mathrm{k}$ dağılım ile karşılaştırılır. Eğer pikselin değeri j. dağılımın 2.5x $\sigma^{2}$ içinde ise piksel bu dağılıma aittir. Arka plan dağılımının modeli $\mathrm{B}$ dağılımdan aşağıdaki gibi elde edilir.

$\sum_{j=1}^{B} w_{j}>T$

Denklem (3)'te T eşik değeri arka plan modeli için dağılım sayısını gösterir. İlk adımda parametreler küçük değerler ile başlatılır. Daha sonra dağılımın ağırlıkları güncellenir. Ağırlık değeri aşağıdaki gibi güncellenir.

$w_{j, t}=(1-\alpha) w_{j, t-1}+\alpha M_{j, t}$

Denklem (4)'te $\alpha$ öğrenme oranını kontrol eder. $M_{j, t}$

değeri ise eşleşen dağılım için 1 ve kalan dağılımlar için 0 değerini alır. Eşleşen dağılım için ortalama ve varyans değeri aşağıdaki gibi hesaplanır. $\mu_{j, t}=(1-\rho) \mu_{j, t-1}+\rho x_{t}$

$\sigma_{j, t}^{2}=(1-\alpha) \sigma_{j, t-1}^{2}+$

$\rho\left(x_{t}-\mu_{j, t}\right)^{T}\left(x_{t}-\mu_{j, t}\right)$

$\rho=\alpha G\left(x_{t}, \mu_{j, t-1}, \sigma_{j, t-1}\right)$

Gaussian karışım modeli üretildikten ve parametreler ayarlandıktan sonra görüntünün bütün pikselleri modele verilmektedir. Her piksel için arka plan veya ön plana ait olma olasılıkları hesaplanır. Büyük olan değere göre pikselin ait olduğu model belirlenir.

Arka plan çıkarıldıktan sonra tespit edilen nesnelerin bir kısmı gürültü ve 1şıktan dolayı arka plana ait olabilir. Aynı şekilde arka planın bazı kısımları nesne olarak görülebilir. Bunları ortadan kaldırmak için morfolojik işlemler olarak genişleme ve erozyon operatörleri uygulanmıştır. İlk olarak görüntü üzerinde erozyon işlemi ile gürültüler giderilmekte daha sonra ise genişleme işlemi ile delikler kapatılmaktadır.

Bant üzerinden geçen nesnelerin sayılması ve tespiti için belirli bir bölgede nesne olup olmadığı kontrol edilmiştir. $\mathrm{Bu}$ amaçla Şekil 3'teki algoritma kullanılmıştır.

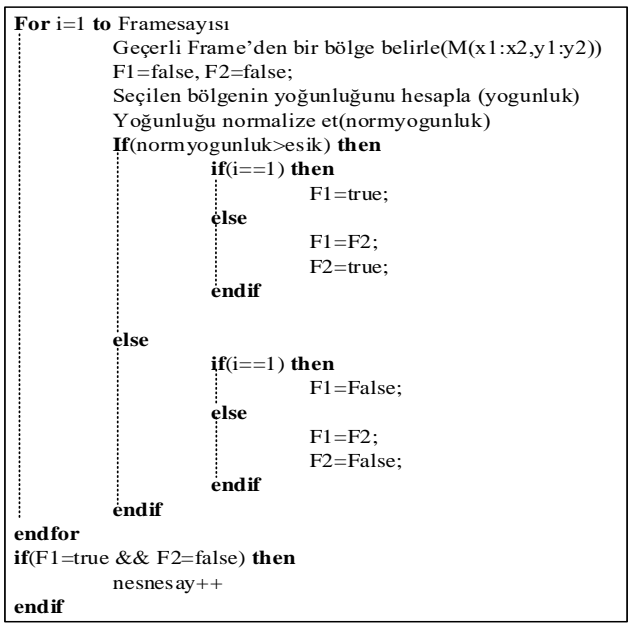

Şekil 3: Nesne tespiti ve sayma

Şekil 3'te verilen algoritmada ardışık iki çerçeve üzerinde nesne tespiti yapılmaktadır. Eğer önceki çerçevede nesne var ve mevcut çerçevede yok ise nesne sayılmaktadır. Tablo 2'de ardışık iki çerçeve için nesne tespitinin bütün durumları verilmiştir.

\begin{tabular}{|c|c|c|}
\hline $\begin{array}{l}\text { Framet-1 } \\
\text { (F1) } \\
\text { False }\end{array}$ & $\begin{array}{l}\text { Frame }_{t} \\
\text { (F2) } \\
\text { False }\end{array}$ & $\begin{array}{l}\text { Nesne tespiti } \\
\text { Nesne yok }\end{array}$ \\
\hline False & True & Nesnenin bölgeye girişi \\
\hline True & False & $\begin{array}{l}\text { Nesnenin bölgeden } \\
\text { ayrılması }\end{array}$ \\
\hline True & True & Nesne halen bölgede \\
\hline
\end{tabular}

Tablo 2: Ardışık iki frame için nesne tespit işleminin olası durumları 
Tablo 2'de eğer F1 ve F2 değerleri false ise son iki frame'de nesne gelmediğinden sayma işlemi yapılmayacaktır. Eğer önceki frame'de bir nesne yok ve mevcut frame'de nesne var ise yeni bir nesne alana giriş yapmıştır. Önceki frame'de nesne var ve mevcut frame'de yok ise nesne bölgeden ayrıldığından sayma işlemi yapılacaktır. İki ardışık frame'de de bölgede nesne var ise sayma yapılmayacaktır. Şekil 4'te önerilen yöntemin bir örnek üzerinde gösterimi verilmiştir.

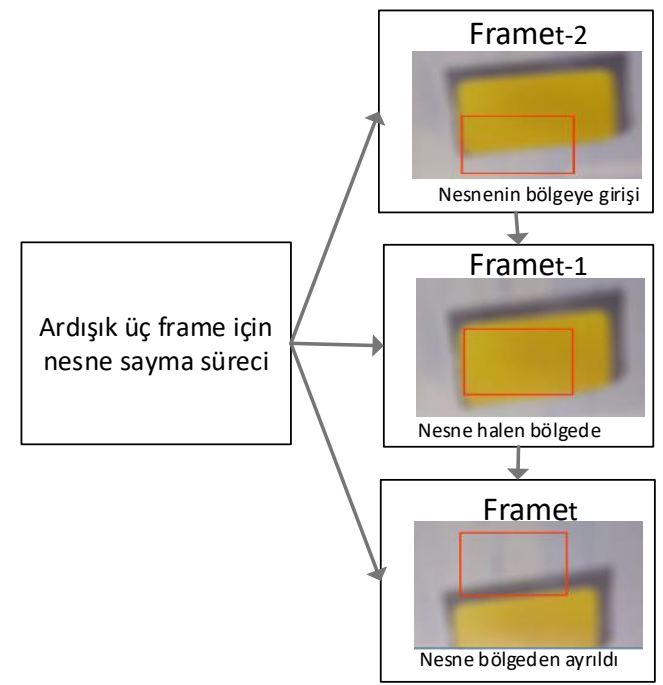

Şekil 4: Ardışık üç çerçeve için nesne sayma işlemi

Şekil 4'te üç ardışık frame için nesnelerin belirlenen bölgeye girişi, bölgede kalması ve çıkışı gösterilmiştir. Sayma işlemi ardışık iki frame'e göre yapılmaktadır. Şekil 4'ten de görüldüğü gibi eğer nesne önceki frame'de bölgenin içinde ve mevcut frame'de ise bölgeden ayrılmış ise sayma işlemi yapılacaktır.

Eğer nesneler birbirine çok yakın ise veya bir nesnenin bir kısmı diğer nesne üzerinde olması durumunda örtüşme olacağından yanlış sayma işlemi oluşabilir. Bu iki durum Şekil 5'te gösterilmiştir.

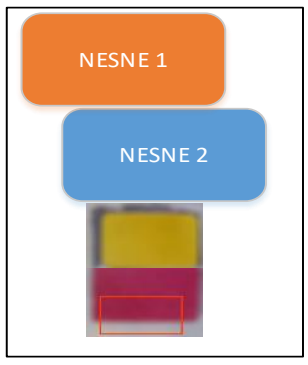

Durum-1

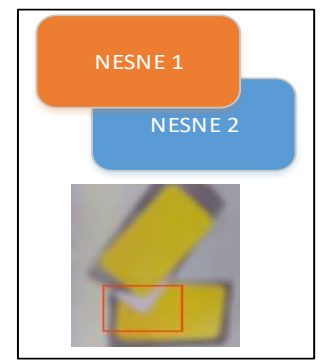

Durum-2
Şekil 5. İki nesnenin örtüşmesi durumu

Şekil 5'teki iki durumdan biri oluştuğu anda nesneleri farklı olarak tespit etmek için her bir nesnenin kontur grafiği elde edilmektedir. Daha sonra convex hull metodu ile iki nesne birleştirilmektedir. Nesne sayma işlemi yapıldığında aynı zamanda nesnelerin merkez noktalarının bulunarak konturu çizilecektir. Bu amaçla görüntü momentlerinin bulunması gerekmektedir.
Arkaplan çıkarımı yapılan ikili görüntü için uzaysal moment aşağıdaki gibi hesaplanır.

$$
m_{j i}=\sum_{x, y} I(x, y) \cdot x^{i} \cdot y^{i}
$$

Denklem (8)'de I(x,y) belirlenen pozisyondaki görüntü pikselini ifade eder. Merkez momentler aşağıdaki gibi hesaplanır.

$$
m u_{j i}=\sum_{x, y} I(x, y) \cdot(x-\bar{x})^{j}(y-\bar{y})^{i}
$$

Denklem (9)'da $\bar{x}$ ve $\bar{y}$ kütle merkezini göstermekte olup aşağıdaki gibi hesaplanır.

$$
\bar{x}=\frac{m_{10}}{m_{00}}, \bar{y}=\frac{m_{01}}{m_{00}}
$$

Görüntü momentleri bulunduktan sonra ikili görüntünün merkezi tespit edilmekte ve ikili görüntünün kontur grafiği elde edilmektedir. Convex hull ile nesnelerin etrafını çizmek için ikili görüntüde en soldaki nokta bulunmaktadır. Daha sonra bu noktadan diğer noktalara gidilerek nesnenin etrafı çizilmektedir. Şekil 6'da bu işlemin adımları verilmiştir.

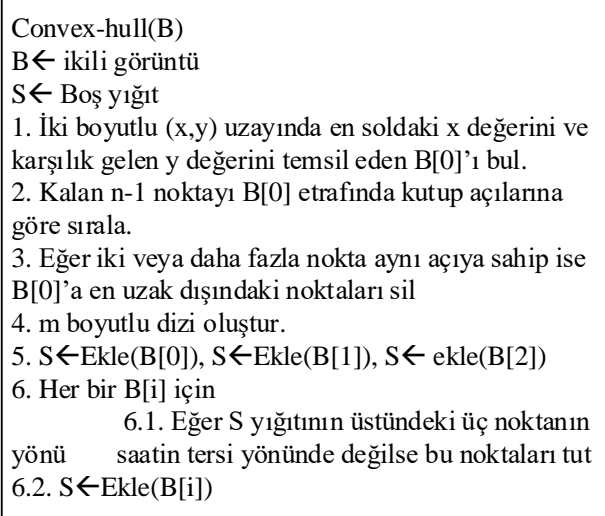

Şekil 6. Convex-hull köşe noktalarının tespiti

Her bir nesnenin oranı ile birleştirilmiş nesnelerin alanları arasındaki oran bir eşik değer ile karşılaştırılarak çift nesne olup olmadığı tespit edilmektedir.

\section{Deneysel Sonuçlar}

Önerilen bu yaklaşım ile gerçek zamanlı çalışan bir üretim bandındaki ürünlerin saydırılması işlemi gerçekleştirilmiştir. Bu amaçla ortaya konan bilgisayar görmesi tabanlı kalite kontrol uygulaması ile bu işlem hızlı ve sorunsuz bir şekilde gerçekleştirilmiştir. Önerilen yaklaşımın doğrulaması gerçek zamanlı endüstriyel bir sistemden alınan videolar üzerinde yapılmıştır. Diğer bölümlerde de belirtildiği üzere çalışmalar açık kaynaklı bir görüntü işleme kütüphanesi olan OpenCV ve $\mathrm{C}++$ programlama dili kullanılarak 
gerçekleştirilmiştir. Endüstriyel sistemden alınan bu videolar bir kalite kontrol kamerası aracılığıyla elde edilmiştir. Kalite kontrol sisteminde kullanılan bu kameranın temel özellikleri Tablo 3 'te verildiği gibidir.

Tablo 3. Kalite kontrol sisteminde kullanılan kameranın temel özellikleri

\begin{tabular}{ll}
\multicolumn{2}{l}{ Kamera Özellikleri } \\
\hline Özellik & Değer \\
Çözünürlük & $1280 \times 720 \mathrm{px}$ \\
Frame Oranı & $59 \mathrm{fps}$ \\
Shutter Türü & Global \\
Sensör Türü & CCD \\
Mono/Color & Color \\
Arayüz & GigE \\
Piksel Bit Derinliği & 12 bit \\
\hline
\end{tabular}

Gerçekleştirilen bu çalışmada yapılan testlerde farklı durumlar ile karşılaşılmıștır. Bunlardan ilki bant üzerinden geçen ürünlerin renklerinin farklı olmasıdır. Endüstriyel bir sistemden elde edilen görüntülerde temel olarak 2 farklı renk durumu vardır ve bunlar sarı ile kırmızıdır. Ayrıca sistemde kameranın izlediği alanda arka plan tamamen beyaz ile kaplanmıştır. Bu şekilde kontrast değerlerinin oldukça farklı olduğu yapılarda kontrol işlemleri kolaylaşmakta ve daha doğru sonuçlar elde edilebilmektedir. Çalışma süresince karşılaşılan bir diğer durum ise aynı görüntü karesinde iki tane ürünün görünmesidir. Bu durumda ise ya ürünler birbirine çok yakındır ya da üst üste binmiş durumdadır. Yine böylesi durumlarda da sayma işleminin sorunsuz bir şekilde yapılması oldukça önemlidir. Tüm bu durumları örnekleyen deneysel sonuçlar farklı renk durumları için Şekil 7 ve 8'de verilmiştir.

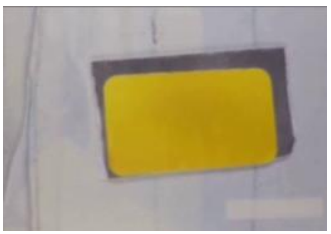

(a)

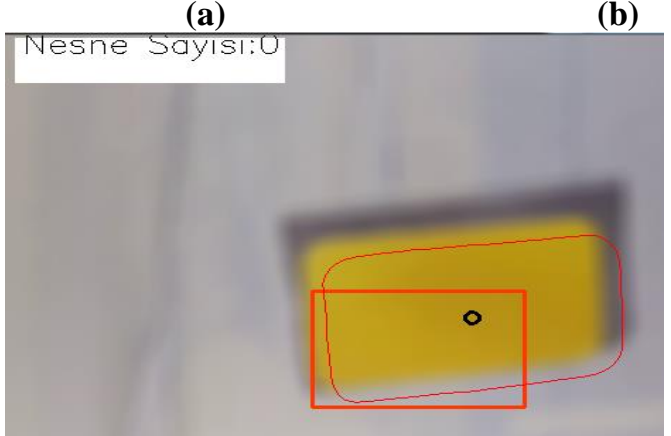

(c)

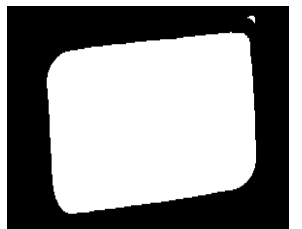

(b)
Şekil 7. Deneysel çalışmalardan elde edilen örnek bir sonuç (a) Orijinal görüntü (b) Arkaplanı çıkarılmış görüntü (c)
Konturları çizilmiş, merkezi işaretlenmiş ve sayma işlemine tabi tutulmuş görüntü karesi

Şekil 7'den de görülebileceği üzere uygulama temel olarak 3 adımdan oluşmaktadır. Bunlardan ilki görüntü karesinin hafizaya yüklenmesidir. Daha sonra arka Plan çıkarımı yapılmaktadır. Daha sonra erozyon ve genişleme gibi morfolojik işlemler uygulanmaktadır. Daha sonra nesnenin konturu çizilmektedir. Bu işlem ile ürünün sınırları tespit edilmekte ve merkez noktası hesaplanabilmektedir. Dikdörtgensel bir alan içinden bir nesnenin geçiş kontrolü yapılmaktadır. Bu belirlenen bölgede bir önceki görüntü çerçevesinde nesne var ve bir sonrakinde yoksa sayma işlemi yapılmaktadır. Literatürde yapılan çalışmalar incelendiğinde genellikle sanal bir çizgi çizilmesiyle yapılan saydırma işlemi, gerçekleştirilen bu çalışmada literatürden farklı olarak siyah-beyaz geçişleri kontrol edilerek yapılmıştır.

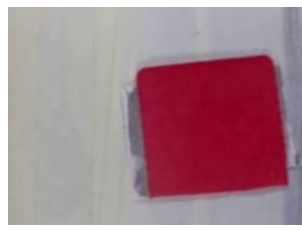

(a)

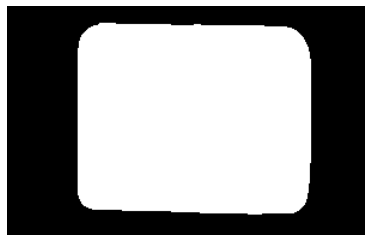

(b)

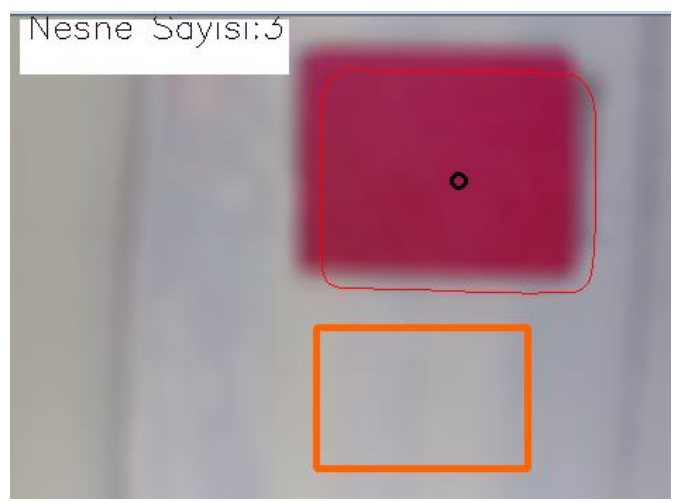

(c)

Şekil 8. Deneysel çalışmalardan elde edilen örnek bir sonuç (a) Orijinal görüntü (b) Arkaplanı çıkarılmış görüntü (c) Konturları çizilmiş, merkezi işaretlenmiş ve sayma işlemine tabi tutulmuş görüntü karesi

Şekil 8'den de görülebileceği üzere çalışma süresince yapılan testlerde iki farklı renk durumu ile karşılaşıılmıştır. Bunlar sırasıyla sarı ve kırmızıdır. Yine bu sonuçta da bir öncekinde olduğu gibi aynı işlemler görüntü karesine uygulanmış ve başarılı sonuçlar elde edilmiştir. Şekil 8 (b) incelenecek olursa, renkli görüntünün arka planı gürültüsüz bir şekilde elde edilmiştir. Çalışma süresince karşılaşılan bir diğer durum olan ürünlerin aynı görüntü karesinde geçmesi durumu ise Şekil 9'da verildiği gibidir. 


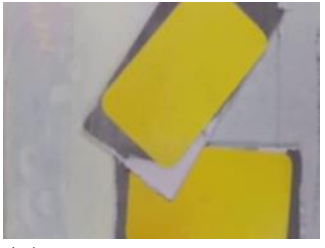

(a)

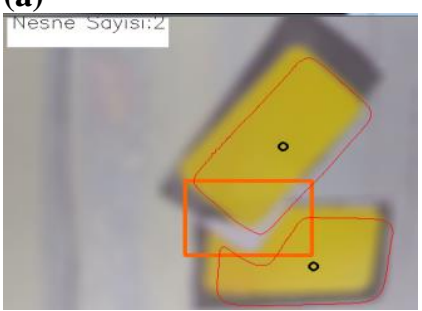

(c)

Şekil 9. Deneysel çalışmalardan elde edilen örnek bir sonuç (a) Orijinal görüntü (b) Arkaplanı çıkarılmış görüntü karesi (c) Konturları çizilmiş, merkezi işaretlenmiş ve sayma işlemine tabi tutulmuş görüntü karesi

Şekil 9'dan da görülebileceği üzere aynı anda iki ürün tek bir görüntü karesinde yer almış durumdadır. Gerçekleştirilen bu çalışmada birbirine yakın gelen ürünlerin sayılması için convex hull yöntemi kullanılmıştır. $\mathrm{Bu}$ yönteme göre birbirine yakın olan nesneler tek bir bölütlenmiş nesneye dönüştürülmekte ve onların alanına göre ve nesnenin belirlenen bölgede ne kadar süre kaldığına göre çoklu nesneler tespit edilmektedir. Şekil 10'da convexhull ile iki nesnenin birleştirilmiş şekli verilmiştir.

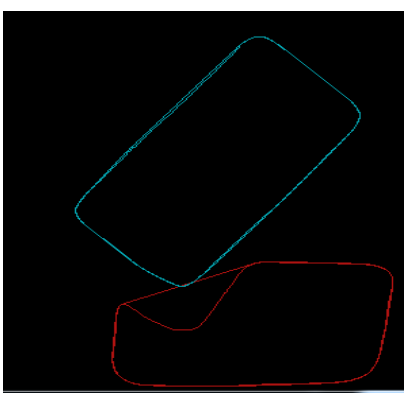

Şekil 10. Yakın şekillerin birleştirilmesi

Nesnelerin doğru bir şekilde sayılabilmesi için daha önce bahsedilen bir eşik değer kullanılmıştır. Bu çalışmada eşik değer 0.3 olarak seçilmiştir. Seçilen bölgedeki normalize edilmiş yoğunluk 0.3 değerinden yüksek ise ilgili bölgede bir nesne olduğu varsayılmaktadır. Bir nesne belirlenen bölgeye girdiğinde eşik değeri artmakta ve bölgenin bütün piksellerinde nesne var ise yoğunluk değeri 1 olmaktadır. Fakat her zaman nesne tam bölgenin içinden geçmeyebilir veya arka plan çıkarımında elde edilen nesnelerde gürültüler olabilir. Şekil 11'da iki farklı nesnenin belirlenen bölgeden geçmesi durumunda hesaplanan yoğunluk değeri verilmiştir.

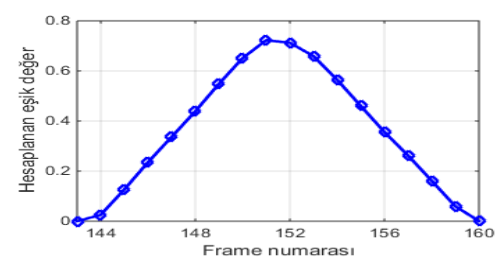

(a) Gürültüsüz nesne için yoğunluk

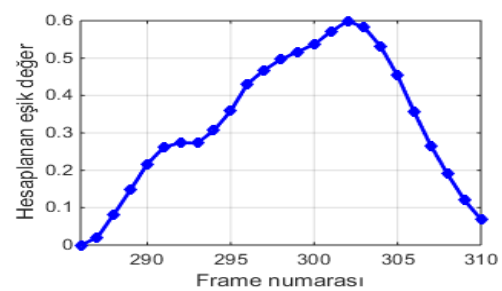

(b) Gürültülü nesne için yoğunluk

Şekil 11. İki farklı durum için belirlenen bölgedeki yoğunluk değişimi

Şekil 11 (a)'da belirli sayıda frame için belirlenen bölgeye nesnenin girişi ile çıkışı arasında ilgili bölgenin normalize edilmiş yoğunluk değişimi düzgün bir dağılım göstermektedir. Eşik değer 0.3 alındığından 11 frame boyunca nesnenin bu alanın içinde olduğu görülmektedir. Şekil 10 (b)'de ise gürültüye sahip olan bir nesnenin belirlenen bölgeden geçmesi ile oluşan yoğunluk değişimi grafiği verilmiştir. Elde edilen grafikte belirli noktalarda düzensiz artışlar olduğu gözlemlenmiştir. Burada temel iki sebep olabilir. Birincisi seçilen nesnenin sadece bir kısmının seçilen dikdörtgenden geçmesi ikincisi ise arkaplan çıkarımı sonucu nesne üzerinde oluşan gürültülerdir. Şekil 12'de iki farklı video için 50 frame boyunca her bir frame'in işleme zamanları verilmiştir.

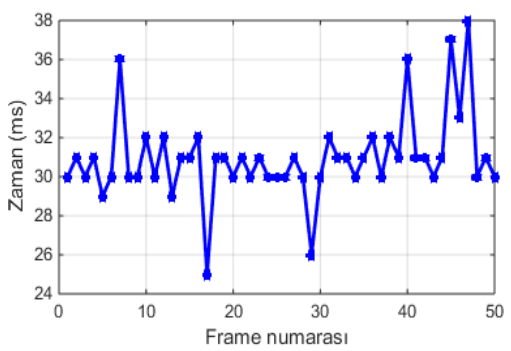

(a) Video-1 için her bir frame'in işleme zamanı

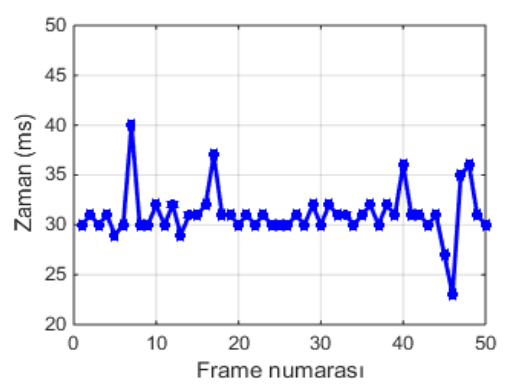

(b) Video-2 için her bir videonun işleme zamanı

Şekil 12. İki video için önerilen yaklaşımın çalışma zamanı 
Gerçekleştirilen bu yaklaşım ile renk ayrımı yapmaksızın hızlı bir üretim bandı üzerinden geçen ürünlerin saydırılması işlemi gerçekleştirilmiştir. Önerilen bu yöntem ile endüstriyel üretim hattında kullanılan bir kalite kontrol kamerasına yazılım geliştirilmiş olup, bant üzerindeki ürünlerin sorunsuzca sayılması sağlanmıştır. Gelecekte yapılacak diğer çalışmalar ile bant üzerinden geçen ürünlerdeki eksikliklerin tespit edilmesi ve kusurlarına göre sınıflandırılması işlemleri gerçekleştirilecektir.

\section{SONUÇ}

Günümüzde endüstriyel üretim bantları gelişen teknolojiyle beraber oldukça hızlı bir gelişim göstermekte ve sürekli olarak kendini yenilemektedir. Teknolojideki gelişmelere paralel olarak büyüyen endüstriyel tesisler, her geçen gün daha fazla üretim kapasitesine ulaşmakta ve ürün portföyünü genişletmektedir. Şüphesiz ki bu durumun en önemli sebeplerinden birisi de kalite kontrol sistemleridir. Özellikle bir uzman aracılığıyla yapılan manuel kontrollere göre çok daha doğru ve hızlı çözümler sunan kalite kontrol sistemleri ile hatasiz, eksiksiz ve problemsiz ürünler elde edilebilmektedir. $\mathrm{Bu}$ durumu sağlayan bir diğer faktör ise kalite kontrol sistemlerinde kullanılan kamera modüllerinin maliyetinin giderek düşmesi ve yüksek performanslı kamera sistemlerinin yine yüksek verim ve doğrulukla çalışabilmesidir.

Gerçekleştirilen bu çalışma ile kalite kontrol sistemlerinde sıklıkla karşılaşılan bir durum olan ürün saydırma işlemi yüksek hız ve doğrulukla ortaya konmuştur. Yapılan çalışmada gerçek zamanlı çalışan bir endüstriyel sistemden alınan örnek videolar ile bir bant üzerinde geçen ürünler incelenmiştir. $\mathrm{Bu}$ amaçlar doğrultusunda OpenCV ve $\mathrm{C}++$ kullanılarak gerçekleştirilen görüntü işleme uygulaması ile ürünlerin belirlenmesi ve saydırılması işlemi gerçekleştirilmiştir. Önerilen yaklaşım ile yüksek hızlı bir video üzerinde herhangi bir zaman sapması olmadan tüm görüntü karelerinin işlenmesi sağlanmıştır. Ayrıca gerçekleştirilen çalışmanın tamamen açık kaynaklı bir kütüphane olan OpenCV kullanılarak gerçekleştirilmesi ve gerçek zamanlı endüstriyel sistemde kullanılacak olması önerilen yaklaşımın bir diğer avantajıdır. Gelecekte yapılacak çalışmalar ile ürünlerdeki eksikliklerin tespit edilmesi, bu eksikliklere göre ürünlerin sınıflandırılması, ürüne ait ölçülerin çıkarılması gibi çeşitli gereksinimlerin sağlanabilmesi hedeflenmektedir.

\section{TEŞEKKÜR}

$\mathrm{Bu}$ çalışma Türkiye Bilim, Sanayi ve Teknoloji Bakanlığı (SANTEZ programı) tarafindan desteklenmiştir. Proje No: 0743.STZ.2014 (TUBITAK Grant No:112D021).

\section{KAYNAKÇA}

[1] Lee K. H., Park T. H. Image segmentation of UV pattern for automatic paper-money inspection, 11th International Conference on Control Automation Robotics and Vision (ICARCV), 1175-1180, 2010.

[2] Lee J. H., Lee J. M., Kim H. J., Moon Y. S. Machine vision system for automatic inspection of bridges, Congress on Image and Signal Processing (CISP), 3, 363366, 2008.

[3] Chen Y. R., Chao K., Kim M. S. Machine vision technology for agricultural applications, Computers and Electronics in Agriculture, 36, 173-191, 2002.

[4] Yoshino K., Miwa M., Kanamaru A., Kanai N. An automatic through-hole inspection system by analyzing laser diffraction pattern, Proceedings of Annual Conference (SICE), 2155-2160, 2010.

[5] Duan G., Chen Y. W., Sakekawa T. Automatic optical inspection of micro drill bit in printed circuit board manufacturing based on pattern classification, Instrumentation and Measurement Technology Conference Proceedings (IMTC), 279-283, 2008.

[6] Khan U. S., Iqbal J., Khan M. A. Automatic inspection system using machine vision, 34th Applied Imagery and Pattern Recognition Workshop (AIPR), 212-217, 2005.

[7] Zhou W., Fei M., Zhou H., Li K. A sparse representation based fast detection method for surface defect detection of bottle caps, Neurocomputing, 123, 406-414, 2014.

[8] Yang S. W., Lin C. S., Lin S. K., Tseng Y. C. Automatic inspection system for defects of printed art tile based on texture feature analysis, Instrumentation Science and Technology, 42, 59-71, 2013.

[9] Yazdi L., Prabuwono A. S., Golkar E. Feature extraction algorithm for fill level and cap inspection in bottling machine. International Conference on Pattern Analysis and Intelligent Robotics (ICPAIR), 1, 47-52, 2011.

[10] Brosnan T., Sun D. W. Inspection and grading of agricultural and food products by computer vision systems-a review, Computers and Electronics in Agriculture, 36, 193-213, 2002.

[11] Torregrosa A., Albert F., Aleixos N., Ortiz C., Blasco J. Analysis of the detachment of citrus fruits by vibration using artificial vision, Biosystems Engineering, 119, 1$12,2014$.

[12] Halfawy M. R., Hengmeechai J. Optical flow techniques for estimation of camera motion parameters in sewer closed circuit television inspection videos, Automation in Construction, 38, 39-45, 2014.

[13] Stoianovic R., Mitropulos P., Koulamas C., Karaviannis Y., Koubias S., Papadopoulos G. Real-time vision based system for textile fabric inspection, Real-Time Imaging, 7, 507-518, 2001.

[14] Cho C. S., Chung B. M., Park M. J. Development of realtime vision-based fabric inspection system, IEEE Transactions on Industrial Electronics, 52, 1073-1079, 2005.

[15] Kumar A. Computer vision based fabric defect detection: a survey, IEEE Transactions on Industrial Electronics, 55, 348-363, 2008.

[16] Jia H., Murphey Y. L., Shi J., Chang T. S. An intelligent real-time vision system for surface defect detection, Proceedings of the 17th International Conference on Pattern Recognition (ICPR), 3, 239-242, 2004.

[17] Ge X. The design of a global shutter CMOS image sensor in $110 \mathrm{~nm}$ technology, Master of Science Thesis, Delft University of Technology, 2012.

[18] Lim S. H. Video-processing applications of high speed cmos image sensors. The Degree of Doctor of Philosophy, Stanford University, 2003. 
[19] Palakodety A. CMOS active pixel sensors for digital cameras: current state of the art. The Degree of Master of Science, University of North Texas, 2007.

[20] Santur, Y., Karaköse, M., Akın, E. Learning Based Experimental Approach for Condition Monitoring Using Laser Cameras in Railway Tracks, International Journal of Applied Mathematics, Electronics and Computers (IJAMEC), 4, 1-5, 2016.

[21] Yetis H., Baygin M., Karaköse M. A New Micro Genetic Algorithm Based Image Stitching Approach for Camera Arrays at Production Lines, The 5th International Conference on Manufacturing Engineering and Process (ICMEP 2016), 25-27 May, 2016.

[22] Karaköse M., Yaman O., Aydin I., Karakose E., RealTime Condition Monitoring Approach of PantographCatenary System Using FPGA, 14th IEEE International Conference on Industrial Informatics (IEEE INDIN 2016), Futuroscope-Poitiers, France, 18-21 July 2016.

[23] Aydin I., Karakose E., Karaköse M., Gençoğlu M.T., Akın E., A New Computer Vision Approach for Active Pantograph Control, IEEE International Symposium on Innovations in Intelligent Systems and Applications (IEEE INISTA 2013), Albena, Bulgaria, 2013. 